\title{
Incidence, root causes, and outcomes of surgical site infections in a tertiary care hospital in Rwanda: a prospective observational cohort study
}

Marie Josée Mukagendaneza ${ }^{2}$, Emmanuel Munyaneza ${ }^{2}$, Esperance Muhawenayo ${ }^{2}$, Dancilla Nyirasebura², Egide Abahuje ${ }^{2}$, John Nyirigira ${ }^{3}$, Jean De Dieu Harelimana ${ }^{4}$, Thierry Zawadi Muvunyi ${ }^{5}$, Florence Masaisa ${ }^{5,6}$, Jean Claude Byiringiro ${ }^{2,5}$, Théobald Hategekimana ${ }^{2}$ and Claude Mambo Muvunyi ${ }^{1,5^{*}}$ (D)

\begin{abstract}
Background: Surgical Site Infections (SSI) are the most reported health acquired infection and common surgical complication in both developed and developing countries. In developing countries such as Rwanda, there is a paucity of published reports on the pattern of SSI, therefore this study aimed at assessing the incidence, risk factors and the antibiotic profile of pathogens responsible of SSI.

Methods: This prospective study included 294 patients admitted between October 10, 2017 and February 12, 2018 to the surgical department of the University Teaching Hospital of Kigali. Patients data were collected using a structured and pretested questionnaire in English version. Regular follow-up was maintained until at least 30 days postoperatively. Samples were collected from suspected wounds and identified using different bacteria culture media. Data were analyzed using Statistical Package for the Social Sciences (SPSS) software word version 20.0. $P$-value $<0.05$ was considered statistically significant.

Results: The overall incidence of SSI was 10.9\%. The associated risk factors were found to be an increased age, ASA class, wound classification, skills and experience of the surgeon, longer duration of surgery ( $>2 \mathrm{~h}$ ), prolonged duration of hospital stay, blood transfusion and emergency surgery. The most common pathogens isolated were Klebsiella ssp (55\%), followed by Escherichia coli (15\%) and Proteus ssp (12\%), Acinectobacter (9\%), Staphylococcus aureus (6\%) and coagulase-negative staphylococci (3\%).The pathogens revealed different levels of antibiotic resistance; amoxy-clavilinic acid (98.8\%), gentamicin (92.6\%), ciprofloxacin (78.1\%) and ceftriaxone (53.3\%). On the other hand, Amikacin and imipinem were the only two most effective antibiotics for all isolated pathogens with 100\% sensitivity.
\end{abstract}

Conclusion: SSI incidence rate was revealed to be within acceptable international ranges. However, multi drug resistance was seen in half of the isolates leaving clinicians with few choices of drugs for the treatment of patients with SSI. Periodic surveillance of bacteria and antibiotic susceptibility coupled with the implementation of strict protocol for antibiotic administration and operative room regulations are important to minimize the burden of SSI with resistant bacteria pathogens.

Keywords: Surgical site infection, Incidence, Microbial etiology, Risk factors

\footnotetext{
* Correspondence: clmuvunyi@gmail.com

${ }^{1}$ Infection Control Unit, Kigali University Teaching Hospital, Kigali, Rwanda

${ }^{5}$ Department of Clinical Biology, School of Medicine and Pharmacy, College

of Medicine and Health Sciences, University of Rwanda, Kigali, Rwanda

Full list of author information is available at the end of the article
}

(c) The Author(s). 2019 Open Access This article is distributed under the terms of the Creative Commons Attribution 4.0 International License (http://creativecommons.org/licenses/by/4.0/), which permits unrestricted use, distribution, and reproduction in any medium, provided you give appropriate credit to the original author(s) and the source, provide a link to the Creative Commons license, and indicate if changes were made. The Creative Commons Public Domain Dedication waiver (http://creativecommons.org/publicdomain/zero/1.0/) applies to the data made available in this article, unless otherwise stated. 


\section{Background}

Surgical Site infections (SSI) are the infection following an invasive surgical procedure and are the most frequently reported hospital acquired infections (HAI) $[1,2]$. SSI is a type of hospital-acquired infection (HAI) that arises following surgery and it is related to the surgical site [3]. Currently, SSI is defined as an infection that happens within 30 days of the operation if no implant is left in place or within 1 year of operation if an implant is left in place [4].

SSI may result in increased morbidity and mortality, prolonged hospital stay, increased hospital readmissions even reoperation and healthcare costs $[5,6]$. It has been reported by numerous studies that diverse surgical specialties were associated with elevated costs next to the development of an SSI in United Kingdom [7-9]. In the United States, for example, SSI is found to be a serious complication with an incidence of 2 to $5 \%$ in patients undergoing surgery complicating approximately 300,000 to 500,000 surgeries per year and costing the health-care system upward of $\$ 1.6$ billion [10,11]. SSI is the most common surgical complications in both developed and developing countries [12]. Fan Y.et al., 2014 reported $4.5 \%$ to be an average incidence of SSI in mainland China from 2001 to 2012 and abdominal surgery to be the most common surgical procedure.

The global estimated prevalence of HAI, at any given time, approximates to 1.4 million. Incidence varies widely across countries and surgical procedures; however, it is estimated to occur in at least $2 \%$ of surgeries [10]. In low- and middle-income countries (LMIC), SSI incidence may be approximately up to 4 times higher than in high-income countries [11]. In sub-Saharan Africa, various study results showed that SSI rate is higher than in developed counties with incidences ranging from 11 to $18 \%[10,12]$.

In Rwanda, findings from retrospective study on HAI conducted at University Teaching Hospital of Kigali indicated that SSI account for $76.8 \%$ of all HAIs in surgical department and that $35 \%$ of children with SSI experienced complications [13]. However, data are lacking the incidences of SSI until 30 days-post operation including discharged patients before that period making difficult to estimate the really burden of SSI. Moreover, the lack of published reports on SSI risk factors, microbial pathogens and their antibiotic profile has negatively impacted the prevention and management of this infection. Therefore, there is a need to explore the extent to, and for which reasons patients develop infection after surgery and the common pathogens involved in SSI in Rwanda.

The aim of the study was to establish the burden of SSI, its risk factors, the etiological bacterial agents associated with SSI and their antimicrobial susceptibility pattern as well as the outcome in patients after surgery in orthopedic and general surgery at University Teaching Hospital of Kigali known as CHUK.

\section{Materials and methods \\ Study design, population and settings}

This was a prospective and descriptive study that included 294 patients admitted to the surgical department at Kigali Teaching Hospital between October 2017 and February, 2018. The present study was approved by Kigali Teaching hospital ethics committee and prior to data collection, written informed consent was sought from participants. The target population for the present study was all patients undergoing surgery either as elective or emergency surgical procedures and developed wound infection within the stipulated duration of this study and who were 18 years old and above. Patients who were having another operation within one month proceeding study period were excluded. All patients were evaluated and followed up from the time of admission until the time of discharge and 30 days postoperatively to determine the incidence of SSI.

In this study, all consecutive patients meeting the inclusion criteria were recruited. The structured and pretested questionnaires were used to collect data. Detailed history regarding each case was recorded, such as age, sex, co-morbid conditions, blood transfusion, antibiotic therapy and preoperative hospital stay. The operations were classified as clean, clean contaminated, contaminated and dirty. Other data including associated risks factors (i.e. diabetes, obesity, etc), use of prophylactic antimicrobial agents, the type and duration of surgery. The wound infection was suspected referring to CDC wound infection classification such as superficial infection, deep infection and organ or space of infection.

\section{Specimen collection and processing}

Post-surgical wound swabs or pus aspirates were collected from the clinical infected surgical sites following laboratory standard procedure for specimen collection. Briefly, the surrounding area of the surgical wound was cleaned with $70 \%$ ethyl alcohol and excess debris from the wound base removed by irrigating with normal saline before collection of two sterile cotton swabs. Swabs were immediately sent to the microbiology laboratory for analysis, to avoid desiccation and to prevent the growth of some species at room temperature that may obliterate the true pathogens.

After the arrival of the specimen at the microbiology laboratory, swabs or aspirates were inoculated on Mac Conkey and 5\% Sheep Blood agar (BA) by rolling the swab over the agar and streaking from the primary inoculums, and aerobically incubated overnight at $37^{\circ} \mathrm{C}$ for $24-48 \mathrm{~h}$. The bacteria were identified using standard guidelines. [14]. The antibiotic susceptibility was 
performed using the standard disc diffusion method following the Clinical and Laboratory Standards Institute (CLSI) guidelines were strictly followed throughout the procedures [15]. After reading the zone diameters, the bacteria were classified as sensitive, intermediate or resistance. Laboratory data (including gram stain, culture results, identification of the bacterial isolates as well as antimicrobial susceptibility) were recorded on a data sheet. Quality control was performed using test strains of E. coli ATCC 25 922, Staphylococcus aureus ATCC 25923, and Pseudomonas aeruginosa ATCC 27853.

\section{Statistical analysis}

All statistical analyses were performed using the Statistical Package for the Social Sciences (SPSS), version 20.0 for Windows (SPSS, Inc. Chicago, IL). First, descriptive statistics, including count and percentage, were used to describe the demographic characteristics of the subjects. The mean and standard deviation were computed for quantitative data variables while Qualitative data were compared using proportion. Bivariate analysis for association between potential risk factors and their potential association with SSI was performed using Chi square (x2) and Fisher's exact tests. $P$-value $<0.05$ was considered statistically significant.

\section{Results}

The mean age of the patients was 40.41 years (standard deviation [SD], 16.7 years), with a range of $18-90$ years. Half of the patients (56.5\%) were between the ages of 26-44 years and the rest were almost equally distributed in the age below 25 years of age (15.7\%) and above 45 years of age (17.3\%). The majority $203(69 \%)$ of the patients were Males and 91 (31\%) were females. Half of the patients (55.4\%) had completed primary school and $24.8 \%$ had finished high school while $16 \%$ were illiterates and only $3.7 \%$ had attained tertiary education. Participants' mean BMI $23.4 \pm 2.5 \mathrm{~kg} / \mathrm{m}^{2}$, with the majority of patients (71\%) having healthy weight, $26.7 \%$ being overweight and only $1.6 \%$ obese. Alcohol consumption was found in $37.1 \%$ of patients whereas only 10 (3.4\%) patients were smokers. Majority of the surgeries (73.8\%) were made of orthopedics cases and cases for general surgery and urology were represented 22.4 and 3.7\%, respectively.

As shown in Table 3, Majority of the surgeries 211 (71.8\%) were performed by licensed Surgeons and 83 (28.25) were performed by Residents in training. There were 142 (48.3\%) elective operations and 152 (51.7\%) emergency operations. Severity of disease, measured using American Society of Anesthesiologists (ASA) score, ranged from healthy (class I) to severe systemic disease, which is a constant threat to life (class IV). High proportions of patients $(71.8 \%)$ were found in the class I.
Majority of operated patients (98.9\%) and all patients who developed SSI were discharge from the hospital while 3 patients died.

\section{Incidence rate of surgical site infections}

The overall incidence of SSI after surgery was 10.2\% (34/ 294) and all of the infections were superficial according to the CDC definition. No infection was identified 30 days after discharged from hospital. Table 1 shows that the incidence of SSI was $10.9 \%$ in patient age group below 25 years and $16.9 \%$ the age group between 26 and 45 years while no SSI was reported in patient age group above 45 years. The incidence of surgical site infections was $13.3 \%$ among male patients compared to $7.7 \%$ among females (Table 1). However, the differences in the incidence of SSI among male and female patients were not statistically significant $(p=0.165)$. The occurrence of SSI was similar in orthopedic surgery (12\%) and general surgery $(12.1 \%)$ while there were no cases of SSI in urology surgery. The SSI rate for emergency procedures (19.7\%) was higher than the SSI rate for elective procedures $(2.8 \%)$, a difference, which was statistically significant $(\mathrm{p}=<0.001)$.

\section{Risk factors associated with SSI development}

Bivariate analysis of risk factors that predict occurrence of SSI is described in the Tables 2 and 3. Several known risk factors for SSI are statistically significant in this

Table 1 Socio-demographic characteristics of participants who had surgery

\begin{tabular}{lllll}
\hline & $\begin{array}{l}\text { Total (\%) } \\
(n=294)\end{array}$ & $\begin{array}{l}\text { N (\%) With } \\
\text { SSI }(n=34)\end{array}$ & $\begin{array}{l}\text { N (\%) Without } \\
\text { SSI }(n=260)\end{array}$ & $p$-value \\
\hline $\begin{array}{llll}\text { Age, Yrs, mean }=40.41 \pm(16.7) \\
\leq 25\end{array}$ & $46(15.7)$ & $5(10.9)$ & $41(89.1)$ & 0.004 \\
$26-45$ & $166(56.5)$ & $28(16.9)$ & $138(83.1)$ & \\
$>45$ & $82(17.3)$ & $1(1.2)$ & $81(98.8)$ & \\
Gender & & & & \\
Male & $203(69)$ & $27(13.3)$ & $176(86.7)$ & 0.165 \\
Female & $91(31)$ & $7(7.7)$ & $84(92,3)$ & \\
Level of Education & & & \\
None & $47(16)$ & $0(0)$ & $47(100)$ & 0.015 \\
Primary & $163(55.4)$ & $19(11.7)$ & $144(88.3)$ & \\
Secondary & $73(24.8)$ & $12(16.4)$ & $61(83.6)$ & \\
Tertiary & $11(3.7)$ & $3(27.3)$ & $8(72.7)$ & 0.396 \\
Smoking & & & & \\
Yes & $10(3.4)$ & $2(20)$ & $8(80)$ & \\
No & $284(96.4)$ & $32(11.3)$ & $252(88.7)$ & \\
Alcohol & & & $166(89.7)$ & \\
Yes & $109(37.1)$ & $15(13.8)$ & $94(86.2)$ & \\
No & $185(62.9)$ & $19(10,3)$ & 1666 \\
\hline
\end{tabular}


Table 2 Clinical and procedure characteristics of participants who had surgery

\begin{tabular}{|c|c|c|c|c|}
\hline & $\begin{array}{l}\text { Total (\%) } \\
(n=294)\end{array}$ & $\begin{array}{l}\text { N (\%) With } \\
\text { SSI }(n=34)\end{array}$ & $\begin{array}{l}\text { N (\%) Without } \\
\text { SSI }(n=260)\end{array}$ & $p$-value \\
\hline \multicolumn{5}{|c|}{$\mathrm{BMI} \mathrm{kg} / \mathrm{m}^{2}$ Mean $=23.4 \pm 2.5$} \\
\hline$<25$ & $180(71)$ & $24(13.3)$ & $156(86.7)$ & 0.481 \\
\hline 25 to $<30$ & $67(26.7)$ & $6(9)$ & $61(91)$ & \\
\hline$\geq 30$ & $4(1.6)$ & $1(25)$ & $3(75)$ & \\
\hline \multicolumn{5}{|l|}{ Diagnosis } \\
\hline Orthopedic & $217(73.8)$ & $26(12)$ & $191(88)$ & 0.473 \\
\hline General & $66(22.4)$ & $8(12.1)$ & $58(87.9)$ & \\
\hline Urology & $11(3.7)$ & $0(0)$ & $11(100)$ & \\
\hline \multicolumn{5}{|l|}{ Type of Surgery } \\
\hline Elective & $142(48.3)$ & $4(2.8)$ & $138(97.2)$ & \\
\hline Emergency & $152(51.7)$ & $30(19.7)$ & $122(80.3)$ & $<0.001$ \\
\hline \multicolumn{5}{|l|}{ Outcome } \\
\hline Discharge & $291(98.9)$ & $34(11.7)$ & $257(88.3)$ & 0.036 \\
\hline Death & $3(1.1)$ & $0(0)$ & $3(100)$ & \\
\hline
\end{tabular}

study. ASA class II and above had a significantly increased incidence of $22.9 \%$ of SSIs compared with ASA class I (7.1\%) $(\mathrm{OR}=3.9 ; 95 \% \mathrm{CI}: 1.9-8.1 ; P<0.001)$. When surgical procedures were grouped by wound classification, SSI incidence was 8.5 times high in contaminated and dirty wounds compared to clean surgical wounds (OR $=8.5$; 95\% CI: $2-35.9 ; p=0.001)$. Procedures performed by Licensed Surgeons were half times less likely to be associated with SSI compared to procedures performed by Residents $(\mathrm{OR}=2.2 ; 95 \% \mathrm{CI}$ : $1.1-4.6 ; p=0.029)$. The duration of the surgery also had an affect; operations lasting for more than $2 \mathrm{~h}$ were associated with SSI more frequently than shorter operations $(\mathrm{OR}=2.2$; 95\% CI: $1.1-4.6 ; p=0.026)$. Other factors that predict occurrence of SSI were transfusion during surgery $(\mathrm{OR}=6.8 ; 95 \% \mathrm{CI}: 2.9-16.3 ; p<0.001)$ and long hospital stay of more than 14 days due to post -operative complications $(\mathrm{OR}=42.3$; 95\% CI: 16.4-108.9; $p<0.001)$.

Ceftriaxone was the only antibiotic prescribed to all operated patients. The timing of prophylactic antibiotics showed some variations but in the majority of

Table 3 Descriptive data and bivariate analyses of surgical risk factors associated with SSI

\begin{tabular}{|c|c|c|c|c|c|}
\hline & Total $(\%)(n=294)$ & N (\%) With SSI $(n=34)$ & N (\%) Without SSI $(n=260)$ & OR $(95 \% \mathrm{Cl})$ & $p$-value \\
\hline \multicolumn{6}{|l|}{ ASA score } \\
\hline ASA I & $211(71.8)$ & $15(7.1)$ & $196(92.9)$ & Reference & \\
\hline ASA II-IV & $83(28.2)$ & $19(22.9)$ & $64(77.1)$ & $3.9(1.9-8.1)$ & $<0.001$ \\
\hline \multicolumn{6}{|l|}{ Wound class } \\
\hline Clean and clean-contaminated & $286(97.3)$ & $30(10.5)$ & $256(89.5)$ & Reference & \\
\hline Contaminated and dirty & $8(2.7)$ & $4(50)$ & $4(50)$ & $8.5(2-35.9)$ & 0.001 \\
\hline \multicolumn{6}{|l|}{ Grade of surgeon } \\
\hline Surgeon & $211(71.8)$ & $19(9)$ & $192(91)$ & Reference & \\
\hline Resident & $83(28.2)$ & $15(18.1)$ & $68(88.9)$ & $2.2(1.1-4.6)$ & 0.029 \\
\hline \multicolumn{6}{|l|}{ Time of prophylaxis } \\
\hline$\leq 15 \min$ & $41(13.9)$ & $4(9.8)$ & $37(90.2)$ & NA & 0.653 \\
\hline $15-30 \mathrm{~min}$ & $248(84.4)$ & $30(12.1)$ & $218(87.9)$ & & \\
\hline $30 \mathrm{~min}-1 \mathrm{~h}$ & $5(1.7)$ & $0(0)$ & $5(100)$ & & \\
\hline \multicolumn{6}{|l|}{ Duration of surgery (hours) } \\
\hline$<2$ & $181(61.6)$ & $15(8.3)$ & $166(91.7)$ & Reference & \\
\hline$\geq 2$ & $113(38.4)$ & $19(16.8)$ & $94(83.2)$ & $2.2(1.1-4.6)$ & 0.026 \\
\hline \multicolumn{6}{|l|}{ Transfusion } \\
\hline No & $266(90.5)$ & $23(8.6)$ & $243(91.4)$ & & \\
\hline Yes & $28(9.5)$ & $11(39.3)$ & $17(60.7)$ & $6.8(2.9-16.3)$ & $<0.001$ \\
\hline \multicolumn{6}{|l|}{ Number of staff in the room } \\
\hline$\leq 6$ & $150(51)$ & $18(12)$ & $132(88)$ & NA & \\
\hline$>6$ & $144(49)$ & $16(11.1)$ & $128(88.9)$ & NA & 0.812 \\
\hline \multicolumn{6}{|l|}{ Hospital stay post-operatively (days) } \\
\hline$\leq 14$ & $246(84)$ & $7(2.8)$ & $239(97.2)$ & Reference & \\
\hline$>14$ & $47(16)$ & $26(55.3)$ & $21(44.7)$ & $42.3(16.4-108.9)$ & $<0.001$ \\
\hline
\end{tabular}


the surgeries (84.4\%), antibiotic prophylaxis was administered within 30 min of surgery with an incidence rate of $12.1 \%$; $13.8 \%$ within 15 min with an incidence rate of 9.8\%; while no cases of infections occurred in $1.7 \%$ of surgery with prophylactic antibiotics administered within 30 to $60 \mathrm{~min}$ prior to incision. However, the differences in the incidence of SSI in the relation to timing of prophylactic antibiotic were not statistically significant $(p=0.653)$. There was also no significant difference in the incidence of SSI when stratified by the number of people present during the surgery: $12 \%$ SSI incidence when 6 people present in the room as compared to $11.1 \%$ with more than 6 people $(p=0.812)$.

\section{Bacterial isolates and their antimicrobial susceptibility profiles}

swabs from all patients with SSI were cultured and tested for antibiotic susceptibility. A positive culture was obtained from 32 out of 34 swabs. As it is depicted from Fig. 1, among the cultures with positive growth, the most common organism was Klebsiella ssp with an incidence of 55\%, followed by Escherichia coli (15\%) and Proteus ssp (12\%). Other bacteria isolated were Acinectobacter (9\%), Staphylococcus aureus (6\%) and coagulasenegative staphylococci (3\%).

As it is demonstrated in Fig. 2, antibiotic sensitivity profiles were reported for the organisms isolated from surgical incision sited in patients with SSI. The pathogens showed very high resistance toward amoxy-clavilinic acid (98.8\%), gentamicin (92.6\%), ciprofloxacin $(78.1 \%)$ and ceftriaxone $(53.3 \%)$. Amikacin and imipinem were the only two most effective antibiotics with $100 \%$ of isolates tested sensitive to both antibiotics.

\section{Discussion}

This study has attempted to estimate the burden of SSI by determining not only its incidence and risk factors, but also the etiological bacterial agents associated with SSI and their antimicrobial susceptibility pattern at a referral and tertiary healthcare institution in Rwanda. To our knowledge, this is the first SSI surveillance study in Rwanda, which describes incidence and associated risk factors of SSI using CDC definitions and 30-day follow-up surveillance.

The finding of this study are based on operated cases, of which, the majority (73.8\%) were made of orthopedics cases and cases for general surgery and urology were represented 22.4 and $3.7 \%$, respectively. In this study, the overall incidence of SSI was $10.9 \%$, which is comparable to the average of $11.8 \%$ in developing countries $[4,16]$.

The incidence reported here appears to be also of the same magnitude as that reported in a study in India (11\%) [17]. However, the incidence rate was higher than those of several developed countries. For example, incidence rates were $1.9 \%$ in the United States, $2.2 \%$ in Europe, $1.6 \%$ in Germany, $1.4 \%$ in England, 1.6\% in France, and $2.0 \%$ in Portugal [18].

The difference observed in the incidence rate of SSI in developed countries compared to developing countries, including Rwanda, may be due to several reasons. These reasons include poor set-up of hospitals (lack of equipment and materials necessary to maintain strict guidelines for asepsis), poor hygiene of patients increasing colonization of skin by bacterial flora, late presentation of patients to healthcare system leading to contaminated wounds, and overwhelmed emergency services due to population burden.

The present findings seem to be consistent with other research which highlighted some SSI risk factors, which are discussed below, such as age, ASA class, wound classification, skill and experience of the surgeon, duration of surgery, blood transfusion and emergency surgery [4, 17]. SSI incidence rate increased with age, which may be due to a poorer immune response and

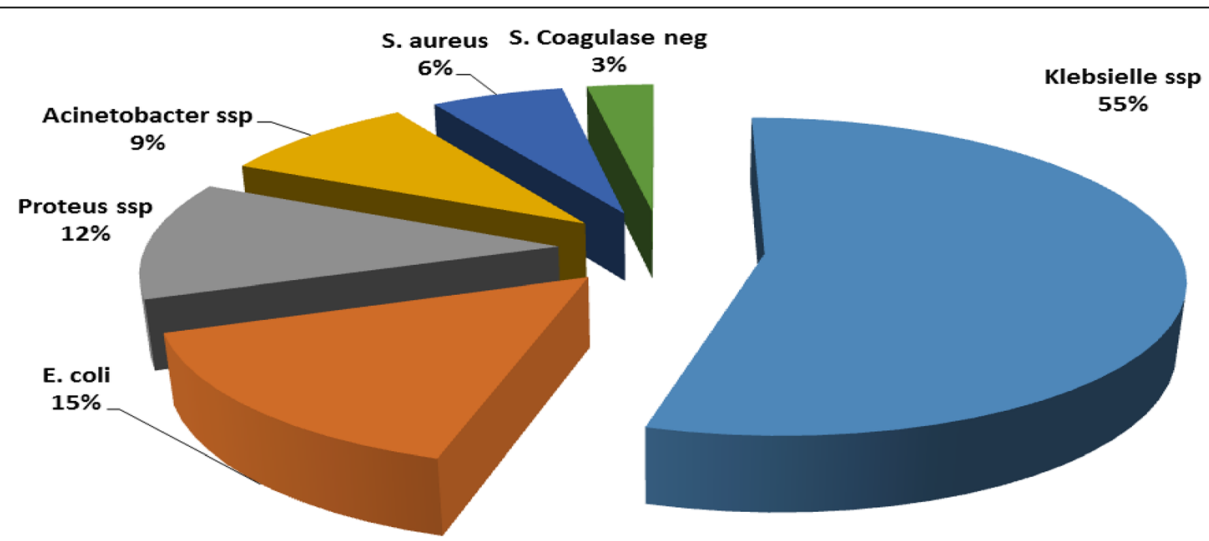

Fig. 1 Distribution of pathogens grown on culture of surgical sites 


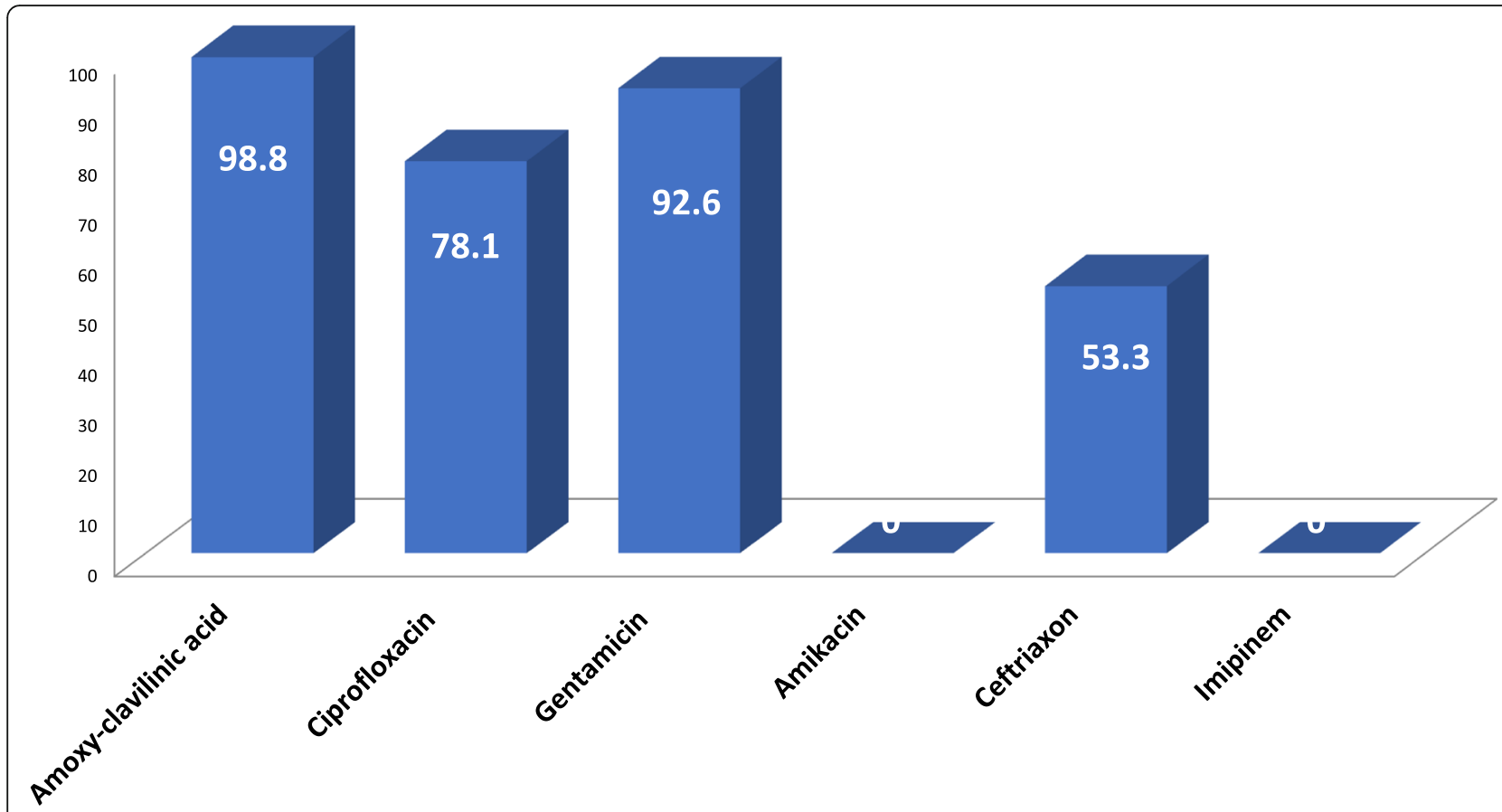

Fig. 2 Antibiotic resistance pattern of SSI isolates

coexistence of other comorbidities. ASA score of 2 or was significantly associated with higher rate of SSI, which may be due to the severity of systemic illness which hinders immunological response in these patients.

SSI incidence rate was higher in contaminated and dirty wounds, not surprisingly, because numerous bacteria, which are the source of the infection, thrive in contaminated/dirty wounds. Consistent with the finding of this study, the skill and grade of the surgeon has been shown to directly affect the incidence of SSI. The more senior and experienced the surgeons, the less likely it was for the patient to develop an SSI.

Two other major risk factors found to be associated with a high incidence of SSI were duration of surgery, which is due to a prolonged exposure of tissue to the environment, prolonged hypothermia and declining levels of antibiotics; long hospital stay, which can be explained by a prolonged stay providing further opportunity for bacterial colonization. Higher rates of SSI in patients who were transfused during surgery can be explained by a reduced Hemoglobin in these patients which may cause hypoxia and impairment in surgical and traumatic tissue oxygenation and healing to favor wound infection.

Emergency surgeries have also been associated with increase in the incidence rate of SSI due like inadequate preoperative preparation, lack of proper control of other medical comorbidities (such as uncontrolled diabetes). Higher frequency of contaminated or dirty wounds in emergency surgeries could also be a contributing factor. Although there was no significant difference in the incidence of SSI in the relation to other potential factors such as timing of prophylactic antibiotic, smoking, BMI, sex, number of staff during, SSI rates seem to be somehow affected by these factors.

In other study, for example, patient factors (smoking, BMI, life style, nutritional status) are associated with resistance of body to germs after operation; similarly, surgical complexity would influence operation duration and exposure possibility $[19,20]$.

Finally, the microorganisms causing SSI and their antimicrobial resistance patterns were evaluated. Klebsiella ssp with an incidence of 55\%, followed by Escherichia coli (15\%) and Proteus ssp (12\%) were the predominant isolate which is in contrast with the finding of other studies. In these studies, S. aureus, has been found to be the predominant cause of SSI, which is can be explained by its presence in the skin as normal flora and can thus enter to deep site during surgery. However, the results of this study agree with the findings of other studies, in which, Klebsiella ssp was found to be the predominant bacteria isolated [21, 22].

This difference in the distribution of SSI bacteria may be due to variation in common nosocomial pathogens inhabitant, difference in policy of infection control and prevention between countries and hospitals. Although there are no clear explanations of about high prevalence of Entero-bacterial isolates in the current study, but faecal contamination due to poor personnel hygiene or due to post procedural contamination and outbreaks could be the possible reasons. 
High resistance rates to commonly used antibiotic, ranging from 53.3 to $98.8 \%$, were observed in bacterial isolates causing SSI in our study. Not surprising, 53.3\% of SSI showed resistance to ceftriaxone, which was prescribed as prophylaxis to all who undergoes surgery. Amikacine and Imipinem were the only effective drugs as $100 \%$ of SSI bacterial exhibited very high sensitivity.

The presence of multidrug resistant bacteria isolated in SSI has also been described in other studies in developing countries. This remarkably higher resistance may be due to their easily availability and inappropriate use of the drugs in our hospitals.

\section{Conclusion}

SSI incidence rate $(10.9 \%)$ was revealed to be within acceptable international ranges. However, multi drug resistance was seen in half of the isolates leaving clinicians with few choices of drugs for the treatment of patients with SSI. There was statistically significant association of SSI with wound class, longer surgery and hospital stay, surgeon experience and grade and emergency surgeries. Therefore, periodic surveillance of bacteria and antibiotic susceptibility coupled with the implementation of strict protocol for antibiotic administration and operative room regulations are important to minimize the burden of SSI with resistant bacteria pathogens.

\section{Abbreviations}

ASA: American Society of Anesthesiologists; CDC: Center for Disease Control; CLSI: Clinical and Laboratory Standards Institute; HAl: Hospital Acquired Infection; LMIC: Low and Middle Income Countries; SPSS: Statistical Package for the Social Sciences; SSI: Surgical Site Infections

\section{Acknowledgements}

The authors would like to thank the management and staff of the hospital for their assistance in facilitating data collection.

\section{Funding}

This study was financially supported by a seed grant from Kigali University Teaching Hospital. The funder had no part in the design of the study, the collection, analysis, and interpretation of data, or in writing the manuscript.

\section{Availability of data and materials}

The datasets analyzed during the current study are available on request from the corresponding author.

\section{Authors' contributions}

MJM, EMN, EMH, DN, EA and CMM were responsible for designing the study, supervising the data collection, performing analysis and interpretation of data, and writing the first draft of manuscript. JN, JDH, FM, TZM, JCB and T $\mathrm{H}$ were actively involved in supervision of the data collection, data analysis, and revision of the initial and final manuscript. All authors read and approved the final manuscript.

\section{Ethics approval and consent to participate}

The study was approved by the Kigali University Teaching Hospital Ethics committee. Written informed consent was obtained from the participants.

\section{Consent for publication}

Not applicable.

\section{Competing interests}

The authors declare that they have no competing interests.

\section{Publisher's Note}

Springer Nature remains neutral with regard to jurisdictional claims in published maps and institutional affiliations.

\section{Author details}

${ }^{1}$ Infection Control Unit, Kigali University Teaching Hospital, Kigali, Rwanda. ${ }^{2}$ Department of Surgery, Kigali University Teaching Hospital, Kigali, Rwanda. ${ }^{3}$ Department of Pharmacy, School of Medicine and Pharmacy, College of Medicine and Health Sciences, University of Rwanda, Kigali, Rwanda. ${ }^{4}$ Department of Biomedical Laboratory Science, School of Health Science, College of Medicine and Health Sciences, University of Rwanda, Kigali, Rwanda. ${ }^{5}$ Department of Clinical Biology, School of Medicine and Pharmacy, College of Medicine and Health Sciences, University of Rwanda, Kigali, Rwanda. ${ }^{6}$ Department of Internal Medicine, School of Medicine and Pharmacy, College of Medicine and health Sciences. University of Rwanda, Kigali, Rwanda.

Received: 15 November 2018 Accepted: 12 February 2019

Published online: 18 February 2019

\section{References}

1. Amenu D, Belachew T, Araya F. Surgical site infection rate and risk factors among obstetric cases of Jimma University specialized hospital. Southwest Ethiopia Ethiop J Health Sci. 2011;21(2):91-100.

2. Fadnis MP, Desai S, Kagal ABR. Original article surgical site infections : incidence and risk factors in a tertiary care hospital. Western. 2012;3(2):152-61.

3. Chahoud J, Kanafani Z, Kanj SS. Surgical site infections following spine surgery: eliminating the controversies in the diagnosis. Front Med [Internet] 2014:1-10. https://doi.org/10.3389/fmed.2014.00007.

4. Fan $Y$, Wei $Z$, Wang $W$, Tan $L$, Jiang $H$, Tian $L$, et al. The incidence and distribution of surgical site infection in mainland China: a meta-analysis of 84 prospective observational studies. Sci Rep. 2014;4:1-8. https://doi.org/10. 1038/srep06783.

5. Andrew B, O'Keeffe TL. \&Stana B. Oxford craniotomy infections database: a cost analysis of craniotomy infection. Br J Neurosurg. 2012;26(2):265-9. https://doi.org/10.3109/02688697.2011.626878.

6. Hogle NJ, Cohen B, Hyman S, Larson E, Fowler DL. Incidence and risk factors for and the effect of a program to reduce the incidence of surgical site infection after cardiac surgery. Surg Infect (Larchmt) [Internet]. 2014;15(3):299-304. https://doi.org/10.1089/sur.2013.048.

7. Pinkney TD, Calvert M, Bartlett DC, Gheorghe A, Redman V, Dowswell G, et al. Impact of wound edge protection devices on surgical site infection after laparotomy: multicentre randomized controlled trial (ROSSINI trial). BMJ [Internet]. 2013;347(7919):1-13. https://doi.org/10.1136/bmj.f4305.

8. Kallala RF, Ibrahim MS, Sarmah S, Haddad FS, Vanhegan IS. Financial analysis of revision knee surgery based on NHS tariffs and hospital costs Does it pay to provide a revision service? Bone Jt J. 2015;97-B(2):197-201. https://doi. org/10.1302/0301-620X.97B2.33707.

9. Atkinson RA, Jones A, Ousey K, Stephenson J. Management and cost of surgical site infection in patients undergoing surgery for spinal metastasis. J Hosp Infect [Internet]. 2017;95(2):148-53. https://doi.org/10.1016/j.jhin. 2016.11.016.

10. Pathak A, Mahadik K, Swami MB, Roy PK, Sharma M, Mahadik VK, et al. Incidence and risk factors for surgical site infections in obstetric and gynecological surgeries from a teaching hospital in rural India. Antimicrob Resist Infect Control. 2017;6(1):1-8. https://doi.org/10.1186/s13756-017-0223-y.

11. Danzmann L, Gastmeier P, Schwab F, Vonberg RP. Health care workers causing large nosocomial outbreaks: A systematic review. BMC Infect Dis. 2013;13(1). https://doi.org/10.1186/1471-2334-13-98.

12. Chu K, Maine R, Trelles M. Cesarean section surgical site infections in subSaharan Africa: a multi-country study from Medecins sans Frontieres. World J Surg. 2015;39(2):350-5. https://doi.org/10.1007/s00268-014-2840-4.

13. Ngendahayo E, Bonane A, Ntakiyiruta G, Munyanshongore A, Muganga N, Bikoroti J, et al. Preparing for safety monitoring after rotavirus vaccine implementation: a retrospective review of intussusception cases among children at a large teaching hospital in Rwanda, 2009-2012. Pediatr Infect Dis J. 2014;33(SUPPL. 1):2009-12. https://doi.org/10.1097/INF. 0000000000000093.

14. Koneman EW, Allen SD, Janda WM, Schreckenberger PCWWJ. Color Atlas and Textbook of Diagnostic Microbiology. 5th ed. Philadelphia: Pa: Lippincott-Raven; 1997. 
15. Wayne P. Performance Standards for Antimicrobial Susceptibility Testing: Twenty-Fifth Informational Supplement [Internet]. Clin Lab Stan Inst. 2015 M100-S25 p. Available from: http://file.qums.ac.ir/repository/mmrc/CLSI2015. pdf. Accessed on 15 Sept 2017.

16. Allegranzi B, Nejad SB, Christophe Combescure LD. Burden of endemic health-care-associated infection in developing countries: systematic review and meta-analysis. Lancet. 2011;377(9761):228-41. https://doi.org/10.1016/ S0140-6736(10)61458-4.

17. Akhter MS, Verma R, Madhukar KP, Vaishampayan ARUP. Incidence of surgical site infection in postoperative patients at a tertiary care centre in India. Wound Care. 2016;25(4):214-7. https://doi.org/10.12968/jowc.2016.25. 4.210

18. Harihara YKT. Surgical site infection (SSI) surveillance. Nihon Geka Gakkai Zasshi. 2006;107(5):230-4

19. Gibbons C, Bruce J, Carpenter J, Wilson AP, Wilson J, Pearson A, et al. Identification of risk factors by systematic review and development of riskadjusted models for surgical site infection. Health Technol Assess [Internet]. 2011;15(30):1-156. https://doi.org/10.3310/hta15300.

20. van Walraven C, Musselman R. The surgical site infection risk score (SSIRS): a model to predict the risk of surgical site infections. PLoS One. 2013;8(6):30-3. https://doi.org/10.1371/journal.pone.0067167.

21. Lubega A, Joel B, Justina LN. Incidence and etiology of surgical site infections among emergency postoperative patients in Mbarara regional referral hospital. South Western Uganda Surg Res Pract. 2017;2017. https://doi.org/10.1155/2017/6365172.

22. Setty NK, Nagaraja M, Nagappa D, Laxmipathy Naik RM, Giriyaiah C, Gowda N. A study on Surgical Site Infections (SSI) and associated factors in a government tertiary care teaching hospital in Mysore, Karnataka. Int J Med Public Heal [Internet]. 2014;4(2):171.

Ready to submit your research? Choose BMC and benefit from:

- fast, convenient online submission

- thorough peer review by experienced researchers in your field

- rapid publication on acceptance

- support for research data, including large and complex data types

- gold Open Access which fosters wider collaboration and increased citations

- maximum visibility for your research: over $100 \mathrm{M}$ website views per year

At BMC, research is always in progress.

Learn more biomedcentral.com/submissions 